\title{
Measuring the Frequency of Inner-Experience Characteristics by Self-Report: The Nevada Inner Experience Questionnaire
}

\author{
Christopher L. Heavey, Stefanie A. Moynihan, Vincent P. Brouwers, \\ Leiszle Lapping-Carr, Alek E. Krumm, Jason M. Kelsey, Dio K. Turner II and \\ Russell T. Hurlburt*
}

Department of Psychology, University of Nevada, Las Vegas, Las Vegas, NV, United States

OPEN ACCESS

Edited by:

Alain Morin,

Mount Royal University, Canada

Reviewed by:

Tanya Luhrmann,

Stanford University, United States

Arnaud Delorme,

UMR5549 Centre de Recherche Cerveau et Cognition (CerCo), France

Glenn Carruthers,

Charles Sturt University, Australia

*Correspondence:

Russell T. Hurlburt

russ@un/v.nevada.edu

Specialty section: This article was submitted to

Cognitive Science,

a section of the journal

Frontiers in Psychology

Received: 25 September 2018

Accepted: 05 December 2018

Published: 11 January 2019

Citation:

Heavey CL, Moynihan SA,

Brouwers VP, Lapping-Carr L, Krumm AE, Kelsey JM, Turner DK II and Hurlburt RT (2019) Measuring

the Frequency of Inner-Experience

Characteristics by Self-Report:

The Nevada Inner Experience

Questionnaire.

Front. Psychol. 9:2615.

doi: 10.3389/fpsyg.2018.02615
Descriptive experience sampling has suggested that there are five frequently occurring phenomena of inner experience: inner speaking, inner seeing, unsymbolized thinking, feelings, and sensory awareness. Descriptive experience sampling is a labor- and skill-intensive procedure, so it would be desirable to estimate the frequency of these phenomena by questionnaire. However, appropriate questionnaires either do not exist or have substantial limitations. We therefore created the Nevada Inner Experience Questionnaire (NIEQ), with five subscales estimating the frequency of each of the frequent phenomena, and examine here its psychometric adequacy. Exploratory factor analysis produced four of the expected factors (inner speaking, inner seeing, unsymbolized thinking, feelings) but did not produce a sensory awareness factor. Confirmatory factor analysis validated the five-factor model. The correlation between an existing self-talk questionnaire (Brinthaupt's Self-Talk Scale) and the NIEQ inner speaking subscale provides one piece of concurrent validation.

Keywords: inner experience, questionnaire, descriptive experience sampling, inner speech, inner seeing, unsymbolized thinking, feelings, sensory awareness

\section{INTRODUCTION}

The term inner experience as we will use it here refers to directly apprehended "before the footlights of consciousness" inner events such as inner speaking, visual images, and sensations. Pristine inner experience refers to inner experiences in their natural state, undisturbed by the act of apprehension, not manipulated by psychological experiment or any other specific intervention (Hurlburt and Akhter, 2006; Hurlburt, 2011).

Descriptive experience sampling (DES; Hurlburt, 1990, 1993, 2011; Hurlburt and Heavey, 2002, 2006; Hurlburt and Akhter, 2006) is an explorational method aimed at pristine inner experience. It uses a random beeper and "expositional" interviews to investigate instances of pristine inner experience. Of course, it falls short-the beep and its response requirements by definition disturb the pristine nature of the experience. Therefore, the aim of DES is to get a glimpse of pristine inner experience in as high fidelity as the current state-of-the-art allows.

The DES method has been described in detail elsewhere (Hurlburt and Heavey, 2006, 2017; Hurlburt, 2011, 2017), and its methodological adequacy has been discussed (Hurlburt and Schwitzgebel, 2007; Caracciolo and Hurlburt, 2016; all the papers in Weisberg, 2011). 
Heavey and Hurlburt (2008) have said that there are five frequent phenomena (subsequently dubbed the " $5 \mathrm{FP}$ " by Kühn et al., 2014) of inner experience: inner speaking (sometimes called "inner speech"; Hurlburt et al., 2013), inner seeing (sometimes called "visual imagery"; Hurlburt, 2011), unsymbolized thinking (a thought directly present without words, images, or other symbols; Hurlburt and Akhter, 2008a,b), feeling (the experience of emotion; Heavey et al., 2012), and sensory awareness (attending to some sensory aspect of the internal or external environment without regard for instrumentality; Hurlburt et al., 2009). Each of the five occurs in roughly a quarter or more of samples (adding to more than 1 because several features can occur simultaneously). To say something like "a characteristic occurs a quarter of the time" implies the necessity of measuring the frequency of these characteristics. Heavey and Hurlburt (2008) measured the 5FP frequencies in the scientifically standard way: they used DES to obtain random samples of inner experience, counted the number of those samples that contain the characteristic and divided by the total number of samples.

Descriptive experience sampling is a labor-intensive procedure, so it would be desirable, if possible, to have a more efficient way of estimating frequency of the 5FP, such as by questionnaire. However, no such questionnaires exist. There are two questionnaires that consider the frequency of inner speech: the Self-Talk Scale (STS: Brinthaupt et al., 2009) and the Varieties of Inner Speech Questionnaire (VISQ; McCarthyJones and Fernyhough, 2011; and the revised version VISQ-R, Alderson-Day et al., 2018). The STS has two frequency-related limitations. First, it does not inquire directly about frequency in natural settings. Instead, the STS inquires about frequency in specific situations, by presenting the stem "I talk to myself when..." followed by a list of situations such as "I should have done something differently," or "I want to reinforce myself for doing well" (Brinthaupt et al., 2009, p. 88). There is no measure of how frequent those situations are and therefore no way of translating to overall natural-setting frequency. Second, it uses anchors $(1=$ Never, $2=$ Seldom, $3=$ Sometimes, $4=$ Often, and $5=$ Very Often) that are ambiguous: "Often" might refer to five times a day ("I often brush my teeth") or five times a year ("Hurricanes often make landfall in the US"). Despite these limitations, the STS is occasionally used as an overall frequency measure (Brinthaupt et al., 2015) by recoding the ratings from 0 to 4 instead of 1 to 5 , adding them, and dividing by 64 (the possible sum of scores), a procedure that assumes (with little warrant) equality of frequency across situations and across people.

The VISQ (McCarthy-Jones and Fernyhough, 2011) is a questionnaire designed to measure features of inner speech inspired by Vygotsky. Like the STS, it has two frequency-related limitations. First, instead of inquiring about frequency directly, it asks about Vygotsky-inspired characteristics of inner speech. Second, it uses ambiguous anchors $(1=$ Certainly does not apply to me, 2 = Possibly does not apply to me, 3 = If anything, slightly does not apply to me, $4=$ If anything, applies to me slightly, $5=$ Possibly applies to me, and $6=$ Certainly applies to $m e$ ), which are not really measures of frequency at all. Here is a typical item: "I hear the voice of another person in my head. For example, when I have done something foolish I hear my mother's voice criticizing me in my mind" (McCarthy-Jones and Fernyhough, 2011, p. 1589); there is no measure of how frequent "doing something foolish" is, and no direct way of mapping applies to me onto frequency. The recently revised version (VISQ-R, Alderson-Day et al., 2018) reduces the anchor ambiguity by using as anchors $1=$ Never to $7=$ All the time, but the VISQ-R remains a consideration of the characteristics of inner speech when it occurs, not a measure of its frequency of occurrence.

There are questionnaires inquiring about emotion (e.g., the Positive and Negative Affect Scale; PANAS; Watson et al., 1988), but such questionnaires typically rate the intensity of emotion, not the frequency of feelings. There are questionnaires inquiring about visual imagery (e.g., the Vividness of Visual Imagery Questionnaire; VVIQ; Marks, 1973), but those questionnaires typically rate vividness of imagery, not its frequency. There are, that we know of, no questionnaire measures at all for unsymbolized thinking or sensory awareness as DES defines them.

Many psychologists believe that inner experience is important for both theoretical and practical reasons. Using inner speech as an example, theoretically, Baddeley and Jarrold (2007) held that inner speech instances are recitations in a phonological loop designed to keep information readily at hand. Practically, inner speech is held to be important, for example, in a wide variety of sport (basketball, football, golf, tennis, cricket, cross country running, swimming, volleyball and many others) performance (Hardy, 2006; Van Raalte et al., 2014), in psychotherapy (Meichenbaum, 1977), in self-awareness and metacognition (Morin, 2005, 2011; Carruthers, 2011), and so on. However, claims about the frequency of inner speech vary widely, from "Human beings talk to themselves every moment of the waking day" (Baars, 2003, p. 106) to the $28 \%$ found by Heavey and Hurlburt (2008). Any theory about the role of inner speech in information processing, sport success, psychotherapy, and so on must account for or dismiss claims about individual differences in inner speech frequency (Hurlburt et al., 2013).

Thus, inner experience (including inner speech) is important, and the measurement of the frequency of inner experiences is a basic scientific endeavor. DES is the best method we know of for such frequency measurement; however, DES is time intensive, so it would be desirable to estimate frequencies by questionnaire. Current questionnaires, if they exist at all for inner phenomena, typically measure characteristics such as vividness rather than frequency, and their response anchors are often ambiguous.

To overcome all those limitations, we created a questionnaire (the Nevada Inner Experience Questionnaire; NIEQ) that (a) inquires about the same inner phenomena that DES frequently finds (the NIEQ has five subscales, one for each of the 5FP); (b) inquires directly about the frequency of experience, rather than its vividness, etc. (by asking "How frequently do you...?" and "Generally speaking, what portion of your inner experience is...?"); (c) inquires about frequency in the natural environment (not about a specified list of situations or a specified list of characteristics); and (d) reduces the ambiguity of anchors by using visual-analog scales (Wewers and Lowe, 1990) with anchors 
from Never to Always (for the "How frequently do you...?" questions) or from None to All (for the "Generally speaking, what portion of your inner experience is. . ?” questions). The complete

TABLE 1 | The Nevada Inner Experience Questionnaire (NIEQ).

\section{Nevada Inner Experience Questionnaire About Your Own Experience}

Please place marks on lines below to indicate the characteristics of your own inner experience. Here's a sample mark:

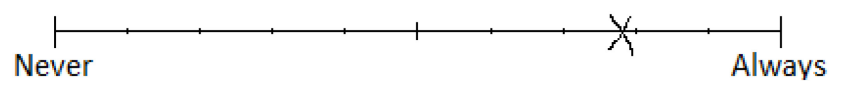

1. How frequently do you talk to yourself in your inner voice?

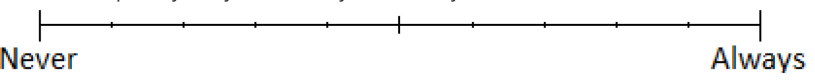

2. How frequently do you mentally see or visualize something?

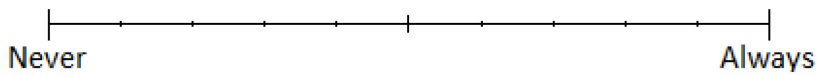

3. How frequently do you feel any emotion such as sadness or happiness or fear?

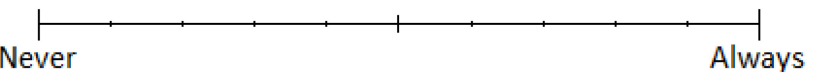

4. How frequently do you pay attention to the colors, smells, or sounds or your environment?

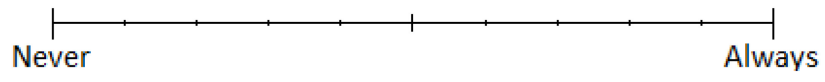

5. How frequently do you experience thoughts without words, images, or feelings?

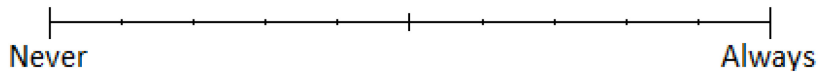

6. Generally speaking, what portion of your inner experience is in inner speech (thinking in words)?

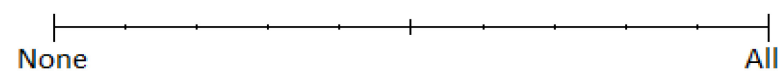

7. Generally speaking, what portion of your inner experience is in images (seeing things in your imagination)?

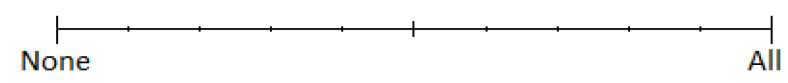

8. Generally speaking, what portion of your inner experience consists of feelings (the experience of emotions like happiness, sadness, excitement, dread, etc.)?

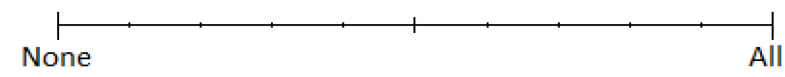

9. Generally speaking, what portion of your inner experience consists of focusing on internal or external sensory experiences, like a tickle or pain, or the color or shape of something you are seeing?

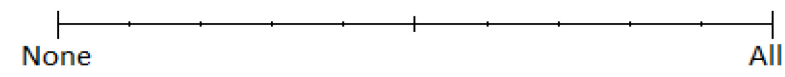

10. Generally speaking, what portion of your inner experience consists of thinking about something specific but without using any words or mental images?

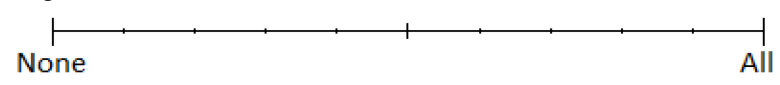

NIEQ is shown in Table 1. The present study investigates the psychometric adequacy of the NIEQ.

\section{MATERIALS AND METHODS}

\section{Participants}

The participants were undergraduate subject-pool volunteers $(N=260)$ taking introductory psychology courses at a large urban university. It was a diverse sample: mean age $=20.6$ years $(S D=4.35$; range $=18-49) ; 28.5 \%$ male, $63.5 \%$ female, $8 \%$ did not provide gender information; $39 \%$ self-identified as white or Caucasian, 17\% Hispanic, 15\% African American, 15\% Asian, and $8 \%$ Pacific Islander. Each received subject-pool credits for participation.

\section{Instruments}

The Self-Talk Scale (STS; Brinthaupt et al., 2009)

The STS is a 16-item questionnaire that uses 5-point frequency scales $(1=$ Never, $5=$ Very Often $)$ to ask about the frequency of self-talk in various situations. It thus produces a total score between 16 and 80. Brinthaupt et al. (2009) showed that the STS has adequate test-retest reliability $[r(99)=0.66, p<0.001]$ over a 3-month period. The STS defines self-talk as including either aloud self-talk or inner speech, without differentiating the two.

\section{Nevada Inner Experience Questionnaire (NIEQ)}

The NIEQ is a 10 -item set of visual-analog scales with one pair of items (a Frequently item and a Generally item) for each of the 5FP. The scale items were written collaboratively by a team of researchers familiar with DES. One question ("How frequently. . .?") was aimed at the participant's perception of how frequently they experience the phenomenon without regard for any other phenomena, whereas the other question ("Generally speaking, what portion...?") used softer language to evoke the participant's perception of how frequently they experience the phenomenon, with an appreciation for time spent engaged in other phenomena. Thus, the two items of each pair were designed to ask basically the same question in two different ways. For example, the two inner speech items are "How frequently do you talk to yourself in your inner voice?" rated on a visual analog scale from Never to Always; and "Generally speaking, what portion of your inner experience is in inner speech (thinking in words)?" rated on a visual analog scale from None to All. The complete NIEQ questionnaire is shown in Table 1. The visual analog scales were treated as running from 0 to 100 . Measurement was doubleentry (Barchard and Pace, 2011): Two raters independently measured each rating (for example, the "sample" mark in Table $\mathbf{1}$ would be measured as 78). The correlation between raters was $>0.99$ for each item. Where between-rater ratings differed by 3 or more, two independent judges resolved the discrepancy. The rating for each item was entered as the average of the two raters. Ratings for each item pair were averaged to produce subscale scores for the frequencies of inner speaking (averaging items 1 and 6), inner seeing (items 2 and 7), unsymbolized thinking (items 5 and 10), feelings (items 3 and 8), and sensory awareness (items 4 and 9). 
TABLE 2 | NIEQ item and scale means (and standard deviations), percentages ${ }^{\mathrm{a}}$, and STS score and percentage.

\begin{tabular}{|c|c|c|c|c|c|c|c|}
\hline Item & ISpeaking & ISeeing & UnsTh & Feeling & SensAw & STS Score & STS percentage ${ }^{b}$ \\
\hline Frequently & $70.7^{\mathrm{C}}(22.1)$ & $71.0(24.0)$ & $40.6(29.5)$ & $79.2(19.0)$ & $72.8(21.4)$ & & \\
\hline Generally & $65.9(19.9)$ & $61.2(24.0)$ & $35.0(25.7)$ & $69.4(22.5)$ & $51.0(23.7)$ & & \\
\hline Scale ${ }^{d}$ & $68.3(17.1)$ & $66.1(20.7)$ & $37.8(23.4)$ & $74.3(17.9)$ & $61.9(17.5)$ & $59.0(9.9)$ & $67.2(15.4)$ \\
\hline
\end{tabular}

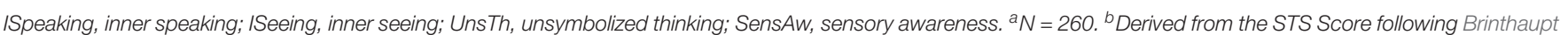

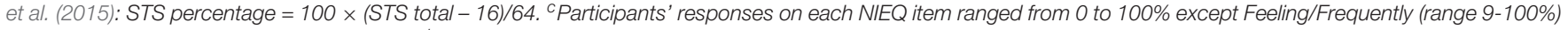
and Unsymbolized/Generally (range 0-98\%). ' ${ }^{d}$ Scale score = average of Frequently item and Generally item.

TABLE 3 | NIEQ item correlations ${ }^{\mathrm{a}}$.

\begin{tabular}{|c|c|c|c|c|c|c|c|c|c|c|}
\hline & & \multicolumn{4}{|c|}{ Frequently } & \multicolumn{5}{|c|}{ Generally } \\
\hline & & ISeeing & UnsTh & Feeling & SensAw & ISpeaking & ISeeing & UnsTh & Feeling & SensAw \\
\hline & ISeeing & & 0.01 & 0.14 & 0.33 & 0.10 & 0.49 & -0.01 & 0.16 & 0.18 \\
\hline & UnsTh & & & 0.00 & 0.21 & -0.07 & 0.01 & 0.43 & 0.05 & 0.16 \\
\hline & Feeling & & & & 0.20 & 0.11 & 0.22 & -0.03 & 0.48 & 0.22 \\
\hline & ISeeing & & & & & & & 0.07 & 0.29 & 0.34 \\
\hline & UnsTh & & & & & & & & 0.10 & 0.32 \\
\hline & Feeling & & & & & & & & & 0.31 \\
\hline
\end{tabular}

ISpeaking, inner speaking; ISeeing, inner seeing; UnsTh, unsymbolized thinking; SensAw, sensory awareness. ${ }^{a} d f=258$.

\section{A Demographic Form}

Designed for this study, the form asked participants to provide name, preferred phone number, age, race/ethnicity, sex, marital status, education level, and employment.

\section{Procedure}

After obtaining informed consent, participants were administered the STS, NIEQ, and the demographic form. This took approximately $20 \mathrm{~min}$.

\section{RESULTS}

The NIEQ item and scale means (as percentages) and standard deviations are shown in Table 2. As expected, within each phenomenon (inner speaking, inner seeing, etc.), the Frequently and Generally item pairs had similar means (with the possible exception of sensory awareness). For example, the ISpeak subscale suggests that our participants believed that inner speaking occurred on average $68.3 \%$ of the time.

Table 2 also shows the mean STS Score for our participants, as well as the STS percentage, an estimate derived (following Brinthaupt et al., 2015) from the STS Score by recoding the anchors from 0 to 4 (instead of 1 to 5), adding the new item codes, and dividing by 64 (the number of items $\times 4$, the maximum score for each item). Thus, on the STS our participants reported self-talk (including both inner speech and external self-speech) as occurring in $67.2 \%$ of potential situations, a value very close to their NIEQ inner-speaking percentage (68.3\% of the time).

The NIEQ item correlations are shown in Table 3. As expected, within each phenomenon (inner speaking, inner seeing, etc.), the Frequently and Generally item pairs correlated fairly strongly with each other (see main diagonal) and the off-pair item correlations were relatively low (with some exceptions, mostly involving sensory awareness).

Because there is no existing factor model of the NIEQ, we include the results of an exploratory factor analysis in Table 4, which shows the Varimax rotated factor components when the eigenvalues are constrained to be greater than 1. Factors emerge as expected (highest loading on the pair of Frequently and Generally item), so the respective factors are easily named Inner Speaking, Inner Seeing, Unsymbolized Thinking, and Feeling.

TABLE 4 | Varimax rotated factor components of the NIEQ (eigenvalues > 1).

\begin{tabular}{llrrrr}
\hline & & \multicolumn{4}{c}{ Component } \\
\cline { 3 - 6 } Frequently & ISpeaking & ISeeing & UnsTh & Feeling \\
\cline { 3 - 6 } & ISpeaking & 0.643 & 0.411 & -0.056 & 0.140 \\
& ISeeing & 0.204 & 0.831 & -0.037 & -0.015 \\
& UnsTh & -0.049 & 0.027 & 0.780 & -0.062 \\
& Feeling & 0.057 & 0.093 & -0.074 & 0.838 \\
& SensAw & -0.307 & 0.661 & 0.186 & 0.179 \\
& ISpeaking & 0.874 & -0.075 & -0.053 & 0.049 \\
& ISeeing & 0.122 & 0.725 & 0.063 & 0.231 \\
& UnsTh & -0.123 & 0.004 & 0.834 & 0.023 \\
& Feeling & 0.053 & 0.150 & 0.095 & 0.821 \\
& SensAw & 0.157 & 0.239 & 0.509 & 0.403 \\
\hline
\end{tabular}

ISpeaking, inner speaking; ISeeing, inner seeing; UnsTh, unsymbolized thinking; SensAw, sensory awareness. 
TABLE 5 | Goodness of fit statistics for NIEQ confirmatory factor analysis (robust solutions for one- and five-factor models).

\begin{tabular}{lcccc}
\hline Model & CFI & RMSEA (90\% Cl) & AIC & S-B $\chi^{\mathbf{2}}$ \\
\hline One factor & 0.596 & $0.122(0.103-0.140)$ & 99.332 & $169.332(d f=35 ; p<0.001)$ \\
Five factors & 0.939 & $0.056(0.029-0.082)$ & -4.655 & $45.345(d f=25 ; p=0.008)$
\end{tabular}

CFI, Comparative Fit Index; RMSEA, Root Mean Square Error of Approximation; $A / C$, Akaike's Information Criterion; $S-B \chi^{2}$, Satorra-Bentler scaled chi-square statistic.

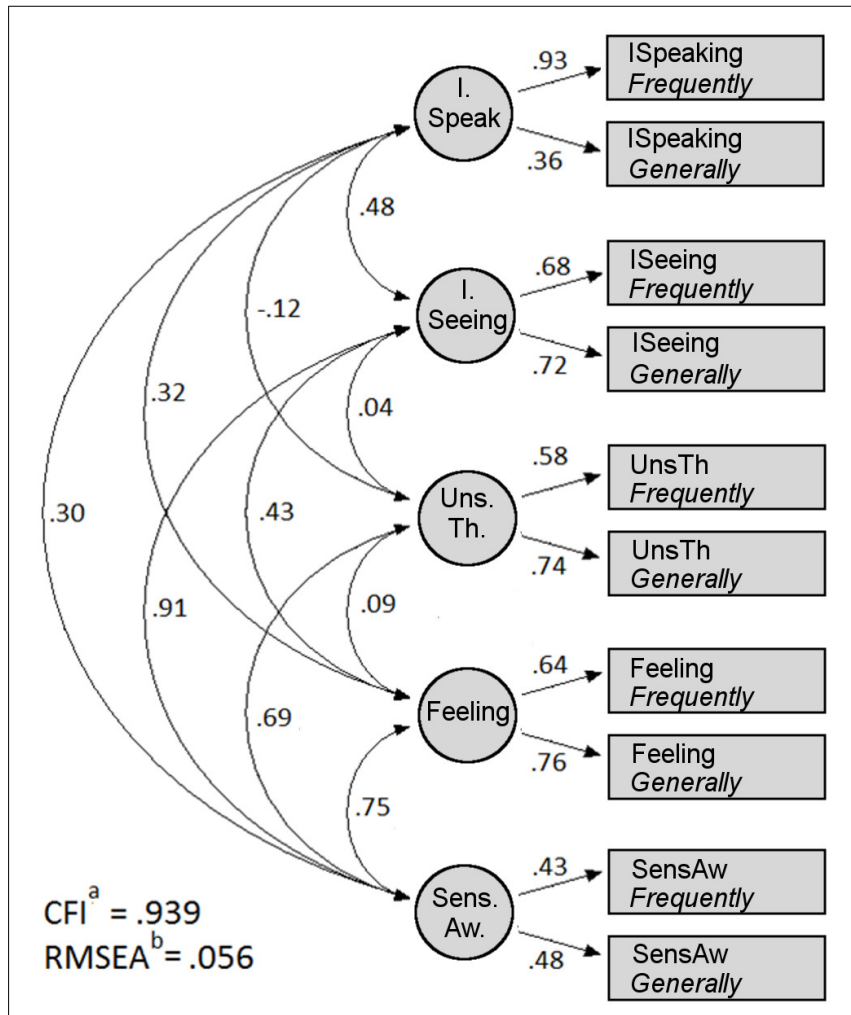

FIGURE 1 | Confirmatory factor analysis of the NIEQ. ISpeaking, inner speaking; ISeeing, inner seeing; UnsTh, unsymbolized thinking; SensAw, sensory awareness. ${ }^{a}$ Comparative Fit Index. ${ }^{b}$ Root Mean Square Error of Approximation.

A sensory awareness factor did not emerge; the sensory awareness items loaded on all the factors.

Because the test construction was designed around a fivefactor model, we used EQS (Bentler, 2008) to conduct two confirmatory factor analyses of the NIEQ, first assuming one factor (to determine whether the NIEQ represents a general inner experience factor) and then five factors (to determine whether the NIEQ reflects the five 5FP factors as designed). Table 5 presents the confirmatory factor analysis goodness of fit statistics. Because Mardia's coefficient for the analysis was 21.38 (that is, greater than 5.00; Bentler, 2008), the data violated assumptions of normality, so robust fit statistics are displayed. The first row of Table 5 shows that the one-factor analysis did not meet the CFI > 0.90 (Bentler, 1990) and RMSEA < 0.08 (Steiger and Lind, 1980) criteria for good fit. However, the second row shows that the five-factor
TABLE 6 | Coefficient alpha (on main diagonal, intercorrelations ${ }^{a}$ of NIEQ subscales, and subscale correlation with the STS).

\begin{tabular}{|c|c|c|c|c|c|c|}
\hline \multicolumn{6}{|c|}{ NIEQ Subscale } & \multirow{2}{*}{$\begin{array}{c}\text { STS } \\
\text { Percentage }\end{array}$} \\
\hline Subscale & ISpeaking & ISeeing & UnsTh & Feeling & SensAw & \\
\hline ISpeaking & 0.50 & 0.30 & -0.13 & 0.21 & 0.08 & 0.52 \\
\hline ISeeing & & 0.66 & 0.02 & 0.27 & 0.43 & 0.27 \\
\hline UnsTh & & & 0.60 & 0.05 & 0.31 & 0.01 \\
\hline Feeling & & & & 0.65 & 0.35 & 0.36 \\
\hline SensAw & & & & & 0.34 & 0.13 \\
\hline
\end{tabular}

ISpeaking, inner speaking; ISeeing, inner seeing; UnsTh, unsymbolized thinking; SensAw, sensory awareness. ${ }^{a} d f=258$.

model provided a much better fit $(\mathrm{AIC}=-4.655)$ than did the one-factor model (AIC =99.332); the Comparative Fit Index was 0.939 and the Root Mean Square Error of Approximation was 0.056 .

The confirmatory factor analysis results for the five-factor model are illustrated in Figure 1. The items typically loaded as expected: one factor was composed primarily of the inner speaking Frequently and Generally items; another primarily of the inner seeing Frequently and Generally items; and so on for each of the five factors. The weakest factor loadings ( 0.43 and 0.48) and strongest between-factor correlations (e.g., 0.91 with inner seeing) involved sensory awareness. Thus, the five-factor model largely (with the possible exception of sensory awareness) supports the structural validity of the NIEQ.

Table 6 shows on the main diagonal coefficient alpha for each of the five NIEQ subscales; these are acceptably high for twoitem scales (between 0.50 and 0.66 ) except for sensory awareness (0.34). The subscale intercorrelations are shown off the diagonal. Again except for sensory awareness, these are, as is desirable, relatively low.

Table 6 also shows the relatively high correlation (0.52) between the NIEQ-ISpeaking subscale and the STS percentage.

\section{DISCUSSION}

The NIEQ was designed to measure directly by questionnaire the five frequent phenomena (5FP) of inner experience identified by DES studies. Psychometric evaluation showed that the NIEQ behaved as it was designed: confirmatory factor analysis showed that the five-factor model was a good fit for the NIEQ items and that the items loaded in the expected way (with the possible exception of sensory awareness).

To situate the NIEQ in the context of other questionnaires, we investigated the relationship of the NIEQ-ISpeaking subscale with the STS (Brinthaupt et al., 2009), a questionnaire that has been used to estimate the frequency of self-talk. We found very similar percentages between the NIEQ-ISpeaking subscale average and the STS frequency average (68.3\% vs. $67.2 \%)$ across our 260 participants; the confidence interval for the difference between the NIEQ-ISpeaking subscale and the STS included zero. [Our STS percentage was somewhat higher than the $58.6 \%$ STS percentage reported by Brinthaupt et al. (2009) and the 
53.9\% reported by Brinthaupt and Kang (2014); we have no explanation for this other than the samples were from different universities.] Furthermore, we found, as expected, a relatively high correlation (0.52) between the NIEQ-ISpeaking subscale and STS. The correlation should not be expected to be higher because (a) whereas the NIEQ-ISpeaking and the STS have substantial overlap (both measure inner speaking), their aims are not identical (the STS, unlike the NIEQ, also includes aloud selftalk, and the STS measures frequency in defined situations, rather than in the natural environment); and (b) there are only two NIEQ-ISpeaking items.

It would be desirable to subject the other NIEQ subscales to similar concurrent validity analysis. We did not do so because, as we have seen, such questionnaires either do not measure frequency (for imagery and feelings) or do not exist (for unsymbolized thinking and sensory awareness).

The NIEQ-SensAw subscale had lower within-scale (Frequently vs. Generally) correlation and higher betweensubscale correlations than the other NIEQ subscales. We offer two potential explanations. First, sensory awareness, as DES defines it, involves a variety of sensations of both the external environment (color, smell, shape, etc.) and inner environment (tickle, soreness, stomach ache, etc.). However, the NIEQ SensAw Frequently item ("How frequently do you pay attention to the colors, smells, or sounds or your environment?") inquires only about the external world, whereas the NIEQ SensAw Generally item ("Generally speaking, what portion of your inner experience consists of focusing on internal or external sensory experiences, like a tickle or pain, or the color or shape of something you are seeing?") inquires about both the inner and the external world. That difference in focus might lower the between-item correlation, even though the two items together may do a better job of measuring sensory awareness as conceptualized in the 5FP than would either item alone.

Second, the concept of sensory awareness does intersect with the other 5FP. For example, feelings can importantly involve sensations (e.g., of a teary eye or a heavy heart); inner seeing may involve a specific sensory focus (e.g., on the color of what is imaginarily seen). Thus, it may be a desirable feature (not a weakness) of the NIEQ to demonstrate the correlation of sensory awareness with other aspects. Further research, including the sampling of experience in the natural environment, is required to tease apart possibilities.

We can compare our results to those derived from LappingCarr (unpublished), which administered the NIEQ as part of a larger study. Those participants $(N=60)$ responded to a Qualtrics version of the NIEQ where they used the mouse to click the NIEQ visual analog scales. Table 7 shows that the results of performing the Varimax-rotated four-factor exploratory factory analysis on Lapping-Carr's unpublished data are very similar to our own results shown in Table 4: Factors emerged as expected (highest loading on the pair of Frequently and Generally item) for Inner Speaking, Inner Seeing, Unsymbolized Thinking, and Feeling, but a sensory awareness factor did not emerge; the sensory awareness items loaded on all the factors. That is, the psychometric conclusions we drew from our own study are consonant with the Lapping-Carr (unpublished) NIEQ data.
TABLE 7 | Varimax rotated factor components derived from Lapping-Carr (unpublished).

\begin{tabular}{llrrrr}
\hline & & \multicolumn{4}{c}{ Component } \\
\cline { 3 - 6 } & & ISpeaking & ISeeing & UnsTh & Feeling \\
\hline \multirow{2}{*}{ Frequently } & ISpeaking & 0.809 & 0.277 & 0.220 & -0.031 \\
& ISeeing & 0.265 & 0.773 & 0.103 & 0.028 \\
& UnsTh & -0.063 & 0.170 & 0.840 & 0.203 \\
Fenerally & 0.189 & 0.094 & 0.117 & 0.750 \\
& Feeling & 0.528 & 0.396 & -0.300 & 0.232 \\
& ISpeaking & 0.729 & -0.254 & 0.108 & 0.419 \\
& ISeeing & -0.149 & 0.877 & 0.238 & 0.203 \\
& UnsTh & 0.275 & 0.184 & 0.786 & 0.151 \\
& Feeling & 0.036 & 0.215 & 0.189 & 0.869 \\
& SensAw & 0.206 & 0.536 & 0.294 & 0.396 \\
\hline
\end{tabular}

ISpeaking, inner speaking; ISeeing, inner seeing; UnsTh, unsymbolized thinking; SensAw, sensory awareness.

Thus, overall we conclude that by the usual psychometric standards, the NIEQ measures the 5FP with consistent estimated frequencies and reliabilities. However, the inner experience frequencies shown in Table 2 (which ranged from 38 to $74 \%$ ) are substantially higher than those reported by Heavey and Hurlburt (2008, p. 6) using DES: inner speech $=26 \%$, inner seeing $=34 \%$, unsymbolized thinking $=22 \%$, feeling $=26 \%$, and sensory awareness $=22 \%$. These discrepancies might be due to the fact that the NIEQ, like the STS, VISQ, and other questionnaires, measures participants' self-reports about inner experience rather than attempting to sample experience itself (Hurlburt et al., 2013). Without training and practice, participants may not have an adequate understanding of their own inner experience, so self-reports (including with the NIEQ) might be expected to over-estimate general experiential frequencies as measured by DES (Hurlburt and Heavey, 2015). We would value studies that seek to measure experience more directly, such as in the experience sampling studies by Brinthaupt et al. (2015) and in DES studies. Now that the NIEQ has been validated as a psychometric instrument, a direct comparison of NIEQ and DES results using the same participants would be desirable.

\section{ETHICS STATEMENT}

This study was carried out in accordance with the recommendations of the UNLV Human Subjects Research Policy of the UNLV Office of Research Integrity, with written informed consent from all subjects. All subjects gave written informed consent in accordance with the Declaration of Helsinki. The protocol was approved by the UNLV Social/Behavioral Sciences Institutional Review Board.

\section{AUTHOR CONTRIBUTIONS}

$\mathrm{CH}, \mathrm{VB}, \mathrm{JK}, \mathrm{DT}$, and RH: planning. $\mathrm{CH}, \mathrm{VB}, \mathrm{LL}-\mathrm{C}, \mathrm{JK}, \mathrm{DT}$, and $\mathrm{RH}$ : NIEQ design and data collection. $\mathrm{SM}$ and $\mathrm{RH}$ : analyses. $\mathrm{CH}$, SM, LL-C, AK, and RH: writing. 


\section{REFERENCES}

Alderson-Day, B., Mitrenga, K., Wilkinson, S., McCarthy-Jones, S., and Fernyhough, C. P. (2018). The varieties of inner speech questionnaire - revised (VISQ-R): replicating and refining links between inner speech and psychopathology. Conscious. Cogn. 65, 48-58. doi: 10.1016/j.concog.2018.07.001

Baars, B. J. (2003). How brain reveals mind: neural studies support the fundamental role of conscious experience. J. Conscious. Stud. 10, 100-114.

Baddeley, A., and Jarrold, C. (2007). Working memory and down syndrome. J. Intellect. Disabil. Res. 51(Pt 12), 925-931. doi: 10.1111/j.1365-2788.2007. 00979.x

Barchard, K. A., and Pace, L. A. (2011). Preventing human error: the impact of data entry methods on data accuracy and statistical results. Comput. Hum. Behav. 27, 1834-1839. doi: 10.1016/j.chb.2011.04.004

Bentler, P. M. (1990). Comparative fit indexes in structural models. Psychol. Bull. 107, 238-246. doi: 10.1037/0033-2909.107.2.238

Bentler, P. M. (2008). EQS 6 Structural Equations Program Manual. Encino, CA: Multivariate Software, Inc.

Brinthaupt, T. M., Benson, S. A., Kang, M., and Moore, Z. D. (2015). Assessing the accuracy of self-reported self-talk. Front. Psychol. 6:570. doi: 10.3389/fpsyg. 2015.00570

Brinthaupt, T. M., Hein, M. B., and Kramer, T. E. (2009). The self-talk scale: development, factor analysis, and validation. J. Pers. Assess. 91, 82-92. doi: 10.1080/00223890802484498

Brinthaupt, T. M., and Kang, M. (2014). Many-faceted Rasch calibration: an example using the self-talk scale. Assessment 21, 241-249. doi: 10.1177/ 1073191112446653

Caracciolo, M., and Hurlburt, R. T. (2016). A Passion for Specificity: Confronting Inner Experience in Literature and Science. Columbus, OH: Ohio State University Press.

Carruthers, P. (2011). The Opacity of Mind: An Integrative Theory of Self-Knowledge. Oxford: Oxford University Press. doi: 10.1093/acprof:oso/ 9780199596195.001.0001

Hardy, J. (2006). Speaking clearly: a critical review of the self-talk literature. Psychol. Sport Exerc. 7, 81-97. doi: 10.1016/j.psychsport.2005.04.002

Heavey, C. L., and Hurlburt, R. T. (2008). The phenomena of inner experience. Conscious. Cogn. 17, 798-810. doi: 10.1016/j.concog.2007.12.006

Heavey, C. L., Hurlburt, R. T., and Lefforge, N. L. (2012). Toward a phenomenology of feelings. Emotion 12, 763-777. doi: 10.1037/a0026905

Hurlburt, R. T. (1990). Sampling Normal and Schizophrenic Inner Experience. New York, NY: Plenum Press. doi: 10.1007/978-1-4757-0289-7

Hurlburt, R. T. (1993). Sampling Inner Experience in Disturbed Affect. New York, NY: Plenum Press. doi: 10.1007/978-1-4899-1222-0

Hurlburt, R. T. (2011). Investigating Pristine Inner Experience: Moments of Truth. Cambridge: Cambridge University Press. doi: 10.1017/CBO978051184 2627

Hurlburt, R. T. (2017). “Descriptive experience sampling," in Blackwell Companion to Consciousness, 2nd Edn, eds M. Velmans and S. Schneider (Malden, MA: Blackwell).

Hurlburt, R. T., and Akhter, S. A. (2006). The descriptive experience sampling method. Phenomenol. Cogn. Sci. 5, 271-301. doi: 10.1007/s11097-006-9024-0

Hurlburt, R. T., and Akhter, S. A. (2008a). Unsymbolized thinking. Conscious. Cogn. 17, 1364-1374. doi: 10.1016/j.concog.2008.03.021

Hurlburt, R. T., and Akhter, S. A. (2008b). Unsymbolized thinking is a clearly defined phenomenon: a reply to Persaud. Conscious. Cogn. 17, 1376-1377. doi: 10.1016/j.concog.2008.07.004

Hurlburt, R. T., and Heavey, C. L. (2002). Interobserver reliability of descriptive experience sampling. Cogn. Ther. Res. 26, 135-142. doi: 10.1023/A: 1013802006827
Hurlburt, R. T., and Heavey, C. L. (2006). Exploring Inner Experience: The Descriptive Experience Sampling Method. Amsterdam: John Benjamins. doi: 10.1075/aicr.64

Hurlburt, R. T., and Heavey, C. L. (2015). Investigating pristine inner experience: implications for experience sampling and questionnaires. Conscious. Cogn. 31, 148-159. doi: 10.1016/j.concog.2014.11.002

Hurlburt, R. T., and Heavey, C. L. (2017). "Inner speaking as pristine inner experience," in Inner Speech: New Voices, eds P. Langland-Hassan and A. Vicente (Oxford: Oxford University Press), 740-753.

Hurlburt, R. T., Heavey, C. L., and Bensaheb, A. (2009). Sensory awareness. J. Conscious. Stud. 16, 231-251.

Hurlburt, R. T., Heavey, C. L., and Kelsey, J. M. (2013). Toward a phenomenology of inner speaking. Conscious. Cogn. 22, 1477-1494. doi: 10.1016/j.concog.2013. 10.003

Hurlburt, R. T., and Schwitzgebel, E. (2007). Describing Inner Experience? Proponent Meets Skeptic. Cambridge, MA: MIT Press.

Kühn, S., Fernyhough, C., Alderson-Day, B., and Hurlburt, R. T. (2014). Inner experience in the scanner: can high fidelity apprehensions of inner experience be integrated with fMRI? Front. Psychol. 5:1393. doi: 10.3389/fpsyg.2014.01393

Marks, D. F. (1973). Visual imagery differences in the recall of pictures. Br. J. Psychol. 64, 17-24. doi: 10.1111/j.2044-8295.1973.tb01322.x

McCarthy-Jones, S., and Fernyhough, C. P. (2011). The varieties of inner speech: links between quality of inner speech and psychopathological variables in a sample of young adults. Conscious. Cogn. 20, 1586-1593. doi: 10.1016/j.concog. 2011.08.005

Meichenbaum, D. (1977). Cognitive-Behavior Modification: An Integrative Approach. New York, NY: Plenum Press. doi: 10.1007/978-1-4757-9739-8

Morin, A. (2005). Possible links between self-awareness and inner speech theoretical background, underlying mechanisms, and empirical evidence. J. Conscious. Stud. 12, 115-134.

Morin, A. (2011). Self-awareness part 2: neuroanatomy and importance of inner speech. Soc. Pers. Psychol. Compass 5, 1004-1017. doi: 10.1111/j.1751-9004. 2011.00410.x

Steiger, J. H., and Lind, J. C. (1980). Statistically based tests for the number of factors. Paper Presented at the Annual Spring Meeting of the Psychometric Society, Iowa City, IA.

Van Raalte, J., Cornelius, A., Copeskey, M., and Brewer, B. (2014). Say what? An analysis of spontaneous self-talk categorization. Sport Psychol. 28, 390-393. doi: 10.1123/tsp.2014-0017

Watson, D., Clark, L. A., and Tellegen, A. (1988). Development and validation of brief measures of positive and negative affect: the PANAS scales. J. Pers. Soc. Psychol. 54, 1063-1070. doi: 10.1037/0022-3514.54.6.1063

Weisberg, J. (ed.) (2011). Describing inner experience: a symposium debating descriptive experience sampling. J. Conscious. Stud. 18, $1-305$.

Wewers, M., and Lowe, N. (1990). A critical review of visual analogue scales in the measurement of clinical phenomena. Res. Nurs. Health 13, 227-236. doi: 10.1002/nur.4770130405

Conflict of Interest Statement: The authors declare that the research was conducted in the absence of any commercial or financial relationships that could be construed as a potential conflict of interest.

Copyright (c) 2019 Heavey, Moynihan, Brouwers, Lapping-Carr, Krumm, Kelsey, Turner and Hurlburt. This is an open-access article distributed under the terms of the Creative Commons Attribution License (CC BY). The use, distribution or reproduction in other forums is permitted, provided the original author(s) and the copyright owner(s) are credited and that the original publication in this journal is cited, in accordance with accepted academic practice. No use, distribution or reproduction is permitted which does not comply with these terms. 